This article has been scanned by iThenticat No plagiarism detected

Volume 3, Issue 3, June 2021

p. 66-73

\title{
DESCRIPTIVE STUDY OF DYSLEXIA AND DYSGRAPHIA SUFFERED BY IRAQI EFL STUDENTS
}

http://dx.doi.org/10.47832/2757-5403.3-3.7

Muna DALAF 1 \& Angham TALIB ${ }^{2}$

\begin{abstract}
:
One of the important topics of research is the topic of "specific learning disorders". Not having the sufficient knowledge about such topic will make the instructors confused when it comes to deal with students who have such disorders. In addition, a great amount of the instructors' efforts and time will be lost. The following study tries to explore the background knowledge of Iraqi EFL college instructors of these disorders. In order to gather the data, two methods were used; the first method is a questionnaire which was given to twenty instructors to be answered. The second method is a number of interviews with a group of other instructors. The results of this study showed that those instructors who participated have contradictory background knowledge about such topic. As a result, it is important to do more workshops that increase the background knowledge of the instructors and make them more capable of dealing with such disorders.
\end{abstract}

Key words: Dyslexia, Dysgraphia, Background Knowledge, Specific Learning Disorders.

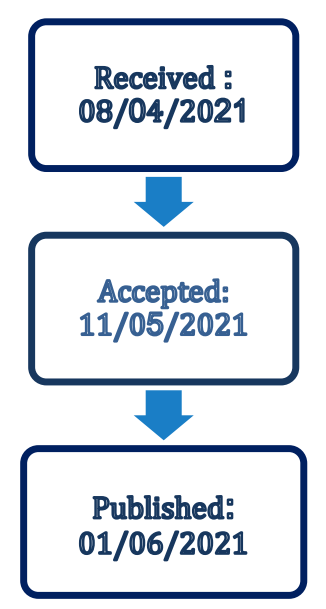

\footnotetext{
${ }^{1}$ Researcher , AL- Mustansiryiah University, Iraq, muna.dalaf@gmail.com, http://dx.doi.org/10.47832/27178293.1-3.21

${ }^{2}$ Researcher, AL- Mustansiryiah University, Iraq, https://orcid.org/0000-0002-2126-4318
} 


\section{Introduction}

In the following study, the focus is on two of the learning difficulties that Iraqi EFL college instructors need to understand more clearly. According to Steinberg, Nagata, and Aline (2013, p.335) there may be two basic kinds of dyslexia. In other words, dyslexia may be divided into two categories. The first one is called 'alexia'. With 'alexia' there is a difficulty in reading. The second one is called 'agraphia'. With 'agraphia' there is a difficulty in writing. The aim of this study is to investigate the background knowledge of Iraqi EFL college instructors towards these two learning difficulties and to make them know how they may act if some of the students whom they teach have such learning difficulties.

The hypothesis of this study is that Iraqi EFL college instructors have contradictory information about such learning difficulties that may be found among their students in the class. The issue of not having much information about how to deal with such learning difficulties may put an additional burden on the instructors' shoulders. Instructors may not know how to properly evaluate some of the students who may suffer from such learning difficulties.

Concerning the procedures, two methods were used. The first method is a questionnaire which was given to twenty Iraqi EFL college instructors who work at different universities to investigate their background knowledge towards these learning difficulties. The other method is a number of interviews with other instructors to know their views and opinions about such learning difficulties and how they may feel about such learning difficulties.

This study is important since it focuses on one of the important topics that many instructors need to understand. With this study, it is hoped that Iraqi EFL college instructors can understand these two learning difficulties. It is also hoped that they understand how to deal with students who may have such difficulties. It is also hoped that college students can benefit from this study and to know how to support any of their colleagues who may suffer from such difficulties.

\subsection{Literature Review}

The first thing to consider is the definitions of these two learning disorders. Payne and Turner (1999, p.3) say that nearly every book that talks about the disorder of dyslexia starts by saying that there are many various ways to define dyslexia. The reason for this thing probably lies in the idea that there are various kinds of specialists who become involved in working or dealing with children who are dyslexic. This includes different types of specialists such as linguists, doctors, teachers and psychologists. The subject of dyslexia will be approached by each of those professionals from a different perspective. In other words, every one of those specialists will look at this subject from a different point of view. The general practitioners will focus only on the physical ailments. Many educational psychologists will focus or concentrate on how children with dyslexia learn. In addition, linguists will approach dyslexia from a different perspective and probably give it a definition in terms of children's language skills. Furthermore, teachers will usually view the matter from a different angle. Teachers will say something like that they are not interested in the way dyslexia is defined, and all what they care about is how to deal with this matter.

Concerning the term, Hall (2009, p.3-4) says that this condition, which is also termed or known as dyslexia, is not a recent one. She also says that -overtime- the terminology of dyslexia was changed somewhat.

Hall (2009, p.3-4) says that the 'specific learning difficulty' term was adopted recently, and such thing reflects the idea that, in its symptoms, this condition or disorder is specific to the individual. In other words, dyslexia is not a generalised disability; dyslexia can be seen as a learning difficulty. One can see that the term 'dyslexia' can present in or appears in various subgroups and forms. She also says that there are developmental dyslexia and acquired dyslexia. The developmental type is most common in children. With teenagers and grownups, acquired dyslexia can appear and it is more common with them. The reason that the acquired type is more common with teenagers and grown-ups is a trauma to the brain. From its name, the acquired type develops after the development of the language, in other words, once the language has developed. As for developmental dyslexia, it appears from very early on.

In general, dyslexia is defined by Aitchison (2003, p.44) as "difficulty with reading". She also says that this term of 'dyslexia' is applied to different types of reading disorders. Such types of disorders may come from an injury 'acquired dyslexia'. Also, these types of disorders may 
come from unknown origin 'developmental dyslexia'. In addition, she also says that some of the types are caused by language problems, while other types are caused by problems with vision. Moreover, she says that dyslexia can be divided into two types 'surface and deep'. In the surface type of dyslexia, the reading errors will have a similarity in the sound to the original. An example of this would be 'beggar' for 'begin'. In the deep type of dyslexia, the reading errors will have a similarity in the meaning to the original. An example of this would be 'fire' for 'heat'.

\subsection{Dyslexia Symptoms}

There are certain types of signs or symptoms for dyslexia. Hall (2009, p.17) gives a number of signs and symptoms for dyslexia. She says that one of the signs is that the short-term auditory memory will function in a poor way. This can have an effect on certain things since it can lead to various things. An example of this is that the person will not be capable of keeping the information for long. Also, the person will have a difficulty in spelling, following instructions, auditory attention, and recalling what he heard. Another sign is a poor visual memory. With such thing, patterns and shapes will be difficult to remember. In addition, there may be an effect on reading and spelling. Tables will also be difficult to remember even if the table was written and in front of the person. Another sign is a poor auditory sequencing. Such thing would lead to a difficulty with the alphabet and with the spelling. It will also lead to a difficulty in the reading comprehension and also a difficulty in following instructions. Also, one of the signs is a poor visuomotor co-ordination. With such thing, there will be difficulties with writing. Moreover, one of the signs is an effect on the visuospatial skill. With such thing, the shape and space perception will be affected. Such thing would lead to a poor handwriting.

Hall (2009, p.17) also says that one of the signs is an effect on the comprehension skill. With such thing, there can frequently be a difficulty in the understanding of the spoken word. With such thing, the person may not be capable of understanding the stories. She also adds that dyslexia can have an effect on the auditory discrimination skill. With such thing, having a struggle in hearing adequate differences can lead to incorrect spelling and reading. The words may also be mispronounced by the person. In addition, one of the signs is an effect on the phonological awareness skill. With such thing, the person may have a difficulty in sequencing the sounds inside the words. One may also have a difficulty in recognizing phonemes and alliteration rhymes. Another effect is that the information processing speed of the person will be poor. This will lead the person to be slower in getting incoming information and a difficulty in the output of the information. The person can also be slower in reading, writing and comprehending.

Hall (2009, p.18) also mentions how dyslexia may affect the fine motor skills. She says that one of the signs is that the person will not be able to maintain the grip. Such thing can make the person put a heavy pressure on pencils and pens. Another sign is that the concept of space and position will be poor. Such thing will make the person will be incapable of keeping between the lines when it comes to writing. In addition, one of the signs is a poor dexterity. Such thing will make the person will have a difficulty in closing buttons and tying shoes. Moreover, dyslexia may also affect the visual perception. One of the signs is a poor visual locating or tracking. With such thing, the person may skip lines when reading. He may also reread lines and has confusion in recognizing similar letters. It is also important to know that people who are dyslexic will lag in the academic subjects. Their self-confidence will often be affected. For dyslexic people, there can be an effect on the social skills and the emotions can be shown in an exaggerated way. In some extreme cases, the person may lose his interest in education and leave school.

\subsection{A University Role}

Concerning this matter, Pollak (2012, p.70) says that the support of the university will be best if it was delivered on-course. In addition, all the staff at the university should be aware of dyslexia. The people who work on promoting the university should also be aware of dyslexia. The websites of the university should also be organized to be easy handled with for people who are dyslexic-. It should not be filled of colors, pictures -especially the ones that move-, and the small text should not be a lot. The websites should be allowed to be 
adjustable or modified in an easier way. In addition, the websites should have the option for a screen reading.

Pollak (2012, p.70) says that it is also essential that the documents of the university should be available in various types of formats. He also says that what is needed is a policy which incorporates all learning differences. Furthermore, it is important to understand that if a university truly wanted to be suitable for such students, then spoken versions of books should be available so that it can be easily accessed. Digital versions are also an option that can help the students who can benefit from them by using text-readers. Also, it is important that there would be another ways to test the students. In other words, there should be replacements for exams. The reason for this thing is that exams require from the students to be fast at handwriting. Exams also require from the students to be capable of producing good spelling and grammar when they are under pressure. Exams will also need from the students to have a high speed of information processing. Moreover, he also says that there should be a replacement for long essays and dissertations. These things require linear thought.

\subsection{Dysgraphia}

Another type of specific learning disorders that students may have is dysgraphia. Dysgraphia is defined by Aitchison (2003, p.44) simply as a "difficulty with writing". She also says that the term of dysgraphia can be used and applied to cover a wide variety of writing disorders.

Concerning handwriting, Payne and Turner (1999, p.9) say that one of the primary effects of dyslexia is on the handwriting. When it comes to handwriting, there are three factors. These factors are: maturity of style, legibility, and the speed of writing. Any deficiencies in any of these can affect the ability of children to perform in a good effective way in the classroom.

In addition, Payne and Turner (1999, p.76) also say that handwriting is essential. As a way of communication, people can be judged by how well their handwritings. At school, the written work of those children who are dyslexic may be undervalued. It is really crucial that the ability of the children to produce clear and acceptable written script should not be undervalued.

Payne and Turner $(1999$, p.97) also summarize some of the common mistakes that dyslexic children do when it comes to handwriting. The first mistake is that dyslexic children start writing the letter from the wrong place. The second mistake is that they form the letter by going in or writing it in the wrong direction. Another mistake that dyslexic children make is that they make the size of the letters too large. An additional mistake is that they make the size of the letters too small. In addition, one of the mistakes that appear is the space between the words themselves. They make the space either too small or too large between the words. Also, the space between the words can be uneven. One of the mistakes is that they find it difficult to make the letters stay on the lines of the paper. Another mistake is that they will find a difficulty with the height of tall letters. In other words, they will make wrong heights for the tall letters. One of the difficulties has to do with the depth of the letter. In other words, they will find a difficulty as they will make the letters descending the wrong depths. Furthermore, one of the difficulties is that they make the slope of the letters inconsistent.

\subsection{Parent's Role}

The parents can also assist their boy who is suffering from these difficulties. According to Selikowitz (1998, p.43) parents often have anxiety about their dyslexic child. Parents worry about how he will act socially and academically at the school. They also worry about how their child will act or manage if he was mocked of. Parents also act in a sensitive way and feel sad about their boy's disappointment and have anxiety because of their boy's concerns. Parents may also feel angry about the teachers who fail in understanding or acting with the problems of their dyslexic child and the doctor who is not capable of describing the learning difficulties of their child. In addition, the wide and different opinions about the condition of the child make many parents confused.

Selikowitz (1998, p.43-44) says that the diverse treatments that are suggested by people can also make the parents confused. Selikowitz (1998, p.44-45) says that the insensitive remarks of the people may also hurt the parents. He also says that there is no unified treatment that will be useful for all parents. For most parents, they find that they can manage and the matter becomes easier with the passage of time. Many parents find that it 
is helpful to have another person to whom they can share their feelings. This can be a friend or a professional person who will hear the feelings of the parents in a sympathetic way and not in a judgmental way. He also says that strategies are needed to be developed by the parents so as to deal with the hurtful remarks that the other people say about their child. It is important to consider this so that one does not feel unprepared in such situations. One of the ways is to say to the other person the things that he said but in a more appropriate way. If someone knows that he will face some unavoidable situation, then it may be important for him to rehearse the situation alone or with someone close to him.

Selikowitz $(1998$, p.45) also adds that parents need to make the other children understand the condition of their dyslexic child. If the child has siblings, then the parents need to make the siblings understand the condition and to let them know that their brother is not lazy. It is also good to make the siblings understand that the parents need to give more time and be with their brother to help him because of his condition. Also, one way in which the parents may help the child to overcome the hurtful remarks from the other peers is to make him imagine as if there was a 'magnetic force field' that prevents the remarks of the other children from reaching to him. It may be helpful to ask the teacher to help the parents. Sometimes, the teacher can start a discussion with the other students about "being different'. Such thing can make the other children change their attitudes.

Building the child's self-esteem is also an important thing to consider. Selikowitz (1998, p.46) says that many children develop a successful mechanism to keep their self-esteem. For the other children, it is essential for the parents to help them in building their selfesteem. Self-esteem is important for children with specific learning difficulties because it will make them try hard and by making them trying hard they will more likely feel success. This will make them feel self-worth. Self-esteem will help the child to cope well and help him when he grows up in life even if his academic capability is limited. Parents can help by accepting the weakness of their child and accepting his feelings without criticizing him. Parents also need to emphasize the positive characteristics of their child and show that they value these characteristics.

Selikowitz (1998, p.47), also says that the child need be encouraged to put realistic goals and it is important to help the child to evaluate the achievements in a realistic way. Also, parents must guide their child to do a suitable activity in a smart way. Parents should also teach their child to praise himself and to praise the other people. Furthermore, parents need to make their child feel belonged to something. One idea that may be good is to make the child join a hobby group. Parents need make their child able to make some of the choices in his life such as selecting things like clothes or taking books from the library. Parents need to admire these choices. An extra way to increase the self-esteem of the child is by enriching the child's experiences by teaching him to do new activities such as gardening.

\section{Research Methodology}

This study is an attempt to investigate the background knowledge of Iraqi EFL college instructors of the 'specific learning disorders'. It tries to see how much information they know about some of the points of these learning disorders.

\subsection{The Population}

In order to get the data, a questionnaire was given to twenty Iraqi EFL college instructors to be answered and give their opinions. Those Iraqi EFL college instructors were chosen randomly from different colleges for the academic year 2020-2021.

\subsection{The Instruments}

To achieve the aim of this study, two tools were used. The first tool is a questionnaire that was given to twenty Iraqi EFL college instructors who work at different colleges. The questionnaire consisted of fifteen items that focus on the topic of the study. It tries to see how much information those instructors know about these two learning disorders. The second tool is a number of interviews with ten instructors to get additional outcomes.

\subsection{Face Validity}

One of the methods in this study is a questionnaire. In order for the measuring instrument to be suitable, it requires 'face validity'. For face validity, Brown $(2001$, p.388) says that face 
validity is a question of whether the test -from the perspective of the learners- measures the things which is supposed to measure. Three of experts were asked to evaluate the questionnaire and to give their advices about it. They accepted the questionnaire but with few minor modifications. The juries are:

Prof. Dr. Abdulkareem Fadhil Jameel (University of Baghdad/ College of Education-Ibn Rushd for humanitarian studies).

Prof. Dr. Duha Attalah Hassan (College of Basic Education/ AL- Mustansiryiah University). Asst. Prof. Abeer, H, Salih. (College of Education for Women/ Al-Iraqia University).

\section{Discussion}

As it was said earlier, one of the methods that were used is a questionnaire. The results of the questionnaire showed variations. With the first item, the number of the instructors who chose 'agree' is twelve (60\%), while the number of the instructors who chose 'disagree' is eight $(40 \%)$. With this point, it must be noticed that dyslexia is the disorder that brings difficulties of reading rhyming words not dysgraphia. With this item, a good number of the instructors did not manage to pick the right answer since they chose 'agree'. With the sixth item, eleven instructors chose 'agree' (55\%), while nine chose 'disagree' (45\%). With this point, it must be seen that problems such as having a difficulty in holding the pen and problems are related to problems with the fine motor skills. With this item, a good number of the instructors managed to pick the right answer since they chose 'agree'. With the fifteenth item, eleven instructors chose 'agree' (55\%), while nine instructors chose 'disagree' $(45 \%)$. With this point, stuttering is something that can be seen with dyslexia not dysgraphia. With this item, a good number of the instructors did not manage to pick the right answer since they chose 'agree'.

For the second item, the number of instructors who chose 'agree' is nine (45\%), while those who chose 'disagree' is eleven (55\%). With this point, such disorders may have an effect not only on the academic skills, but on the social skills as well. A good number of the instructors managed to pick the right answer since they chose 'disagree'. For the third item, four instructors chose 'agree' (20\%), while sixteen chose 'disagree' (80\%). With this point, people with dysgraphia may have difficulties since their handwriting may not be as it should be. A good number of the instructors managed to pick the right answer since they chose 'disagree'. As for the fourth item, the number of instructors who chose 'agree' is seven (35\%), while those who chose 'disagree' is thirteen (65\%). Such types of disorders can affect boys more than girls not girls more than boys. A good number of the instructors managed to pick the right answer since they chose 'disagree'.

With the fifth item, twelve instructors chose 'agree' (60\%), while eight chose 'disagree' (40\%). With this point, it must be seen that people with dyslexia can be gradually improved in their condition, but it is a disorder that continues with the person all the life. A good number of the instructors said that it can be fully cured and chose 'agree'. Those instructors did not manage to pick the right answer. As for the seventh item, eight instructors chose 'agree' $(40 \%)$, while twelve chose 'disagree' (60\%). With this point, people with such disorders may find a difficulty with simultaneous tasks. Concerning the ninth item, nine instructors chose 'agree' (45\%), while eleven chose 'disagree' (55\%). With this point, people with such disorders may have a difficulty with phonological awareness. For the twelfth item, the number of instructors who chose 'agree' is eight (40\%), while those who chose 'disagree' is twelve (60\%). With this point, people with such disorders may have a difficulty in keeping a high attention span. Although for the seventh, ninth and twelfth items, a good number of the instructors answered correctly by choosing 'disagree', it remains important to notice that a good percentage of the other instructors did not manage to do this.

With the eighth item, the number of instructors who chose 'agree' is nineteen (95\%), while only one instructor chose 'disagree' $(5 \%)$. With this point, people with such disorders may find a difficulty with long words. With this item, a high number of the instructors managed to pick the right answer since they chose 'agree'.

For the tenth item, the number of instructors who chose 'agree' is five (25\%), while those who chose 'disagree' is fifteen (75\%). With this point, people with such disorders may have a difficulty in copying from the textbooks and the board. The same thing goes for the eleventh item, the number of instructors who chose 'agree' is five (25\%), while those who chose 'disagree' is fifteen (75\%). With this point, people with such disorders may have a difficulty 
in following instructions. For these two items, a good number of the instructors managed to pick the right answer since they chose 'disagree'.

The number of instructors who said 'agree' for the thirteenth item is twelve (60\%), while eight said 'disagree' $(40 \%)$. With this point, people with such disorders may have a poor short-term memory. A good number of the instructors did not manage to pick the right answer since they chose 'agree'. As for the fourteenth item, eight instructors chose 'agree' $(40 \%)$, while twelve chose 'disagree' $(60 \%)$. With this point, people with such disorders may have a difficulty with timetables. A good number of the instructors managed to pick the right answer since they chose 'disagree'. All in all, there is a variation in the answers and although a good number of the instructors managed to answer correctly, another good percentage of the instructors did not manage to answer correctly. This shows that there is contradictory background knowledge about the topic. As a result it will be helpful to do workshops to increase the background knowledge of the instructors about this topic.

\section{The interviews}

The second tool which is used in this research is a number of interviews with some Iraqi EFL college instructors. The first instructor gave his opinion when he was asked about this topic by saying that it is noticed that many of the instructors are not much familiar with such topics. He said that he may feel that some of the instructors may attribute difficulties like poor handwriting and rough reading to student's laziness. The second instructor shared his opinion by saying that many of the textbooks which are taught focus more on the language. In other words, he said that he may feel that some of the instructors focus more on linguistics and not so much on topics like these. The third instructor said that what most instructors need to know is that students with the specific learning disorders are gifted, but some instructors may not know how to evaluate the academic contribution of such students. Such thing may affect those students and may make them feel as if they do not have the suitable academic abilities.

The fourth instructor gave his opinion by saying that not having the enough background knowledge about such topic may make some of the instructors do not know how to deal with such students. Some instructors may not focus much on such students who have such disorders and make them participate less in some of the learning activities and focus more on the smart students. Such thing may affect the students emotionally as they may feel excluded. The fifth instructor said that some of the instructors may unknowingly comment on the mistakes that such students make in their reading or writing. Such thing may affect the students since it may lessen their feelings of self-esteem.

The sixth instructor said that some of the subjects that the instructors teach are about good writing and good reading. Such instructors expect from the students to develop these language skills. Not having the enough knowledge about such students and their difficulties with reading and writing may make some of the instructors do not give high grades to those students. The seventh instructor gave his opinion about the support that must be given to such students. He said that the instructors are not the only ones who are expected to give the support; the whole staff is also expected to participate in giving the support to such students. The eighth instructor said that it is important to make workshops to the whole staff at the university to enlighten them about such students and how to deal with them. The ninth instructor said that it is helpful to bring professional supervisors who can followup the development of such students and give their advices about the difficulties of every student and how to support them. The last instructor pointed to an important thing which is the tests. Some instructors may make or use the usual forms of the tests. Such traditional forms of tests may add a pressure on the students with such difficulties. Thus, it is helpful to make special types of forms that can be used to test the development of such students.

\section{Conclusions}

This study is an attempt to shed the light on two of the specific learning disorders. The results of the study showed that Iraqi EFL college instructors who participated in this study 
have contradictory background knowledge of these learning disorders. Also, one of the points to see is that there may be a misunderstanding or confusion. It may seem that some of the instructors may think that things like the unorganized handwritings of the students and having a difficulty in reading are just signs of the student's laziness. As a result, it is important to organize more workshops to discuss such matters with the colleges' staff. Such workshops can enlighten the instructors and increase their background knowledge. Instructors need to know that people with such disorders are innovative and can have a successful career in life. The treatment of such students may come from the instructors, the specialists, and the whole university staff when they mix the efforts to help the students with these disorders.

\section{References}

Aitchison, J. (2003). A glossary of language and mind. Oxford: Oxford University Press.

Brown, H. (2001). Teaching by principles: An interactive approach to language pedagogy (2nd ed). White Plains, NY: Longman, Inc.

Hall, W. (2009). Dyslexia in the primary classroom. Exeter: Learning Matters Ltd.

Payne, T., \& Turner, E. (1999). Dyslexia: A parents' and teachers' guide. Clevedon: Multilingual Matters Ltd.

Pollak, D. (2012). Supporting higher education students who are dyslexic. In N. Brunswick (Ed.), Supporting dyslexic adults in higher education and the workplace (pp. 5973). Chichester: John Wiley \& Sons, Ltd.

Selikowitz, M. (1998). Dyslexia and other learning difficulties: The facts (2nd ed). Oxford: Oxford University Press.

Steinberg, D., \& Nagata, H., and Aline, D. (2013). Psycholinguistics: Language, mind and world (2nd ed). Abingdon, Oxon: Routledge. 